Investigations

\title{
Thermal Comfort Investigation in Three Hot-Humid Climate Theme Parks in Jakarta
}

\author{
${ }^{1,2}$ M. Donny Koerniawan and ${ }^{3}$ Weijun Gao \\ ${ }^{I}$ Department of Architecture, Institute Technology of Bandung, Bandung, Indonesia \\ ${ }^{2}$ Department of Architecture, The University of Kitakyushu, Kitakyushu, Japan \\ ${ }^{3}$ Department of Architecture, The University of Kitakyushu, Kitakyushu, Japan
}

Article history

Received: 14-05-2015

Revised: 28-07-2015

Accepted: 03-08-2015

Corresponding Author: M Donny Koerniawan Department of Architecture, The University of Kitakyushu

Kitakyushu, Japan

Email: mdkoerniawan@gmail.com

\section{Introduction}

Over the last years the interesting research on an issue concerning making cities easier to live has considerably grown, some of the most important issues are climatology and thermal comfort. The usefulness of open space and green area, as important elements of the city in giving possibilities for relaxation, physical workout and people interaction, has increased since the awareness of city sustainable development raised. Reported by Landsberg (1981), that outdoor spaces quality contributes to livable quality and generate social interaction. This agreement is similar to the results obtained by several authors (Eliasson, 2000; Oke, 1984; 2006).

In the tropical humid climate cities, open spaces are used during the year and they must provide proper levels of thermal comfort. The condition surrounds buildings, vegetation, shading, water pond and open field influence site environmental conditions. The thermal comfort in open spaces is important for evaluation studies and to guide urban and architectural projects. An extremely important aspect is the understanding of the activities that will take place in a given space so that the planning promotes the user's comfort. Mayer et al. (2008) reported the usage of open public places in cities is more numerous if they propose thermo physiologically comfortable microclimate.

O'Hare (2006) stated the parameters that interfere with thermal comfort in open space are similar to those of inside spaces, but they are more extended and variable. Due to that complexity, in terms of variability, temporality and spatiality, as well as the large possibilities of different activities of the users, the understanding of comfort conditions in these spaces has been the object of many former studies.

Akbari et al. $(2001 ; 2009)$ reported the microclimatic analysis of an open space must consider conditions such as solar incidence and radiation exchanges, local characteristics of wind, topography, vegetation and the presence of water. Bruse (2007) has shown that beyond these factors, the urban design, the morphology of the buildings, the characteristics of the surfaces and the behavior of the individuals are also factors that influence the thermal conditions of these spaces.

Thermal comfort studies are mostly limited to the temperate regions, the lack of thermal comfort indices are shown in the tropical climate region. There are some studies from the tropical climate region could be seen 
from several researchers (Chen and $\mathrm{Ng}, 2012$; Honjo, 2009; Mishra and Ramgopal, 2013). Tropical climate region cities have some challenging conditions; everyday life during the year faces abundant sunshine, solar radiation, high rainfall and high humidity in the tropical climate region cities. Sunshine is about six hours per day. Thus, thermal comfort investigation based on climatology parameters along with human parameters is required in the tropical hot-humid climate.

\section{Jakarta Theme Park}

A theme park is a type of protected area designated by some authorities. Theme Parks in Jakarta are administered by several different agencies. There are three big theme parks in Jakarta, i.e.: (a) Taman Mini Indonesia Indah (TMII); TMII is a recreation park that presents Indonesia Cultures divided into buildings, which every building represents Indonesia Cultures from East to West part of Indonesia; (b) Ragunan Park (Kebun Binatang Ragunan/KBR) is a zoo, second largest zoo in Indonesia after Surabaya's zoo; (c) Taman Impian Jaya Ancol (TIJA) administered by a private company is a modern theme park located at north beach of Jakarta. The position of the three theme parks can be seen in Fig. 1.

The theme park is designed as a part of the city, which provided for recreational use; see the location of the theme parks in the city of Jakarta, Fig. 1. The design of a theme park may determine who is willing to use it. The most important elements of a theme park are attractions as they provide the main reason or motivation for tourists to visit. The aim of purpose-built attractions are to attract visitors and increase visitor numbers, but not all of the attraction in the theme park can be accessed because of the largeness of the theme park and the climatic condition.

\section{Indonesia's Climate Condition}

Figure 1 shows that Indonesia is an archipelago country consist of about 17.000 islands. Break-up by the equator, Indonesia is the distinctly tropical country, almost entirely tropical in climate, with the coastal plains averaging $28^{\circ} \mathrm{C}$, the inland and mountain areas averaging $26^{\circ} \mathrm{C}$ and the higher mountain regions, $23^{\circ} \mathrm{C}$. The east monsoon from June to September brings dry weather while the west monsoon from December to March is moisture laden bringing rain. The transitional period between these two is interposed by occasional rain showers, but even in the midst of the west monsoon seasons, temperatures range from $21^{\circ} \mathrm{C}$ to $33^{\circ} \mathrm{C}$ except at higher altitudes, which are much cooler.

Heaviest rainfalls are recorded in December to January, humidity $(\mathrm{Rh})$ is between 60 to $100 \%$. The main variable of Indonesia's climate is not temperature or air pressure, but rainfall. Almost uniformly warm waters that make up $81 \%$ of Indonesia's area confirm that temperatures on land remain fairly constant.

Java Island is the main island where about $60 \%$ inhabitant of Indonesia lived. Java island where located at the southern part of the equator, the temperature throughout the year between $22^{\circ} \mathrm{C}$ to $29^{\circ} \mathrm{C}$ with humidity average $75 \%$. The wet season happens from October to the end of April and the heaviest rainfall happens between Decembers to February. The dry seasons occur between May to September.



Fig. 1. Map of Indonesia, the land area of Jakarta City and the position of the three big measured theme parks in Jakarta (TMII, TIJA and KBR) 
In general, western and northern part of Indonesia experience the most precipitation than the southern and eastern part of Indonesia; since the northward and westward moving monsoon clouds are heavy with moisture, by the time they reach them more distant regions.

\section{Jakarta's Bioclimatic Characterization}

Jakarta located at $6^{\circ} 13^{\prime} \mathrm{S} 106^{\circ} 50^{\prime} \mathrm{E}$ on the northwest coast of Java; see Fig. 1; at the mouth of the Ciliwung River of Jakarta Bay, which is an inlet of the Java Sea. The city is a lowland area averaging $7 \mathrm{~m}$ above sea level. Officially, the area of the Jakarta Special District (Daerah Khusus Ibukota/DKI) is $662 \mathrm{~km}^{2}$ of land area and $6,977 \mathrm{~km}^{2}$ of the sea area. Rivers flow from the hilly southern parts of the city northwards towards the Java Sea. The most important river is the Ciliwung River, which divides the city into the western and eastern principalities.

The Köppen climate classification stated: Jakarta, located in the western-part of Indonesia in SouthEquator, is a hot and humid equatorial/tropical climate (Af) city. According to the meteorological data in 2013-2014 (Fig. 2), Jakarta's wet season rainfall peak is January with monthly average rainfall 400 millimeters (16 in) and reaches low-point in 70 millimeters (2.8 in) in its dry season in August. In whole years, Jakarta has an average wind speed is $3 \mathrm{~m} \mathrm{sec}^{-1}$ from $270^{\circ}$ (west) with humidity (Rh) range 75-90 and average daily temperatures range from $25^{\circ} \mathrm{C}$ to $36^{\circ} \mathrm{C}$. Thus Jakarta becomes hotter and the hottest month in Jakarta is September-October and the coldest month is in February-March.
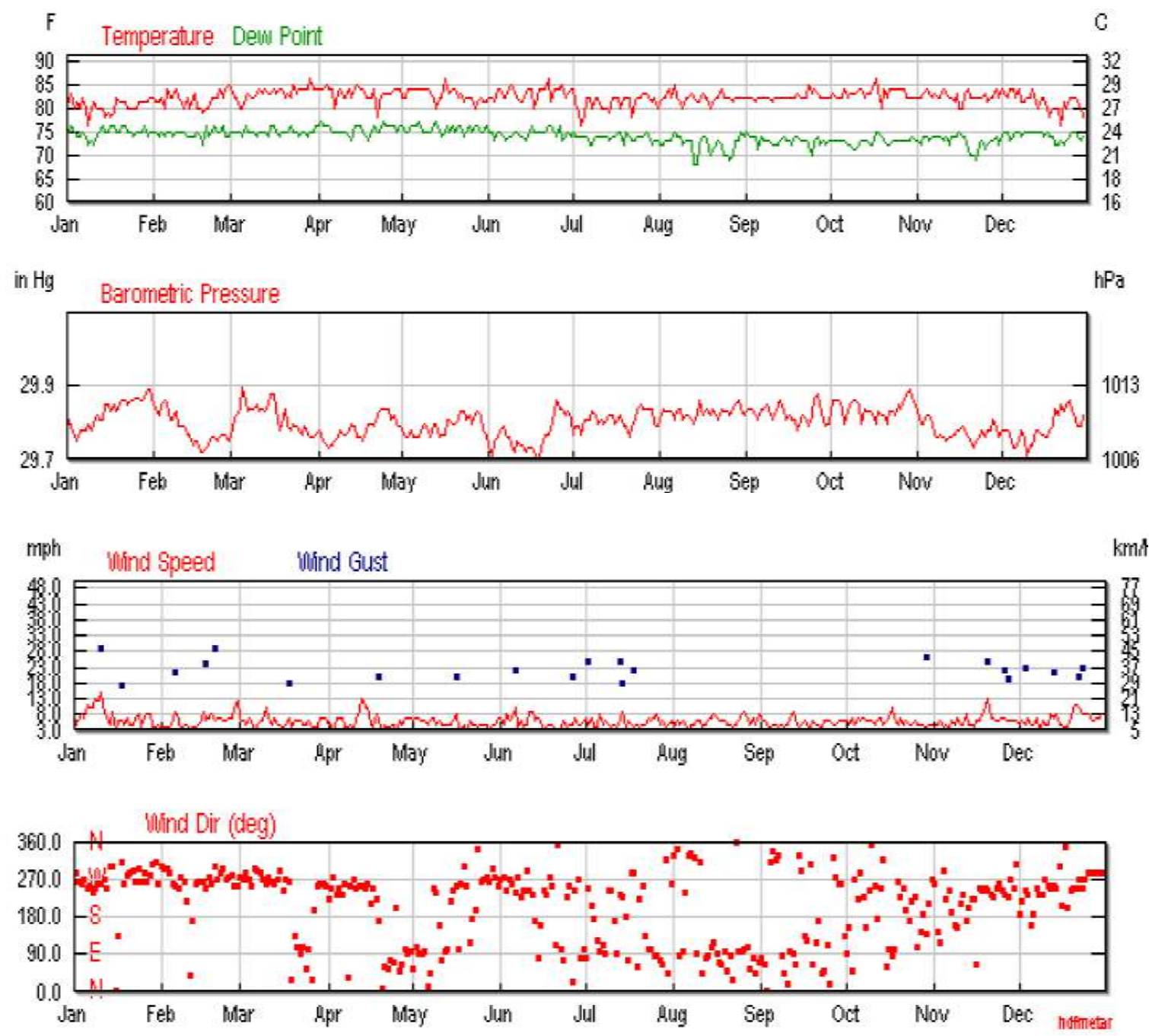

Fig. 2. Seasonal pattern of temperature, air velocity and relative humidity in Jakarta, 2013-2014 (Source: Wunderground.com, 2014) 


\section{Case Study}

\section{Taman Impian Jaya Ancol (TIJA)}

Taman Impian Jaya Ancol (TIJA), known as Ancol Dreamland, is an integral part of the Ancol Bay City, a resort destination located along Jakarta's waterfront $\left(6^{\circ} 07^{\prime} 29.35^{\prime \prime S}, 106^{\circ} 50^{\prime} 35.45^{\prime \prime E}\right)$, see Fig. 1. Ancol
Dreamland opened in 1966 and it is currently the largest integrated tourism area in South East Asia. TIJA with $552 \mathrm{Ha}$ is boasting an international championship golf course, beach theme park, hotels and other recreational facilities. The concept of TIJA theme parks is modern theme parks with modern amusement facilities, see Fig. 3.

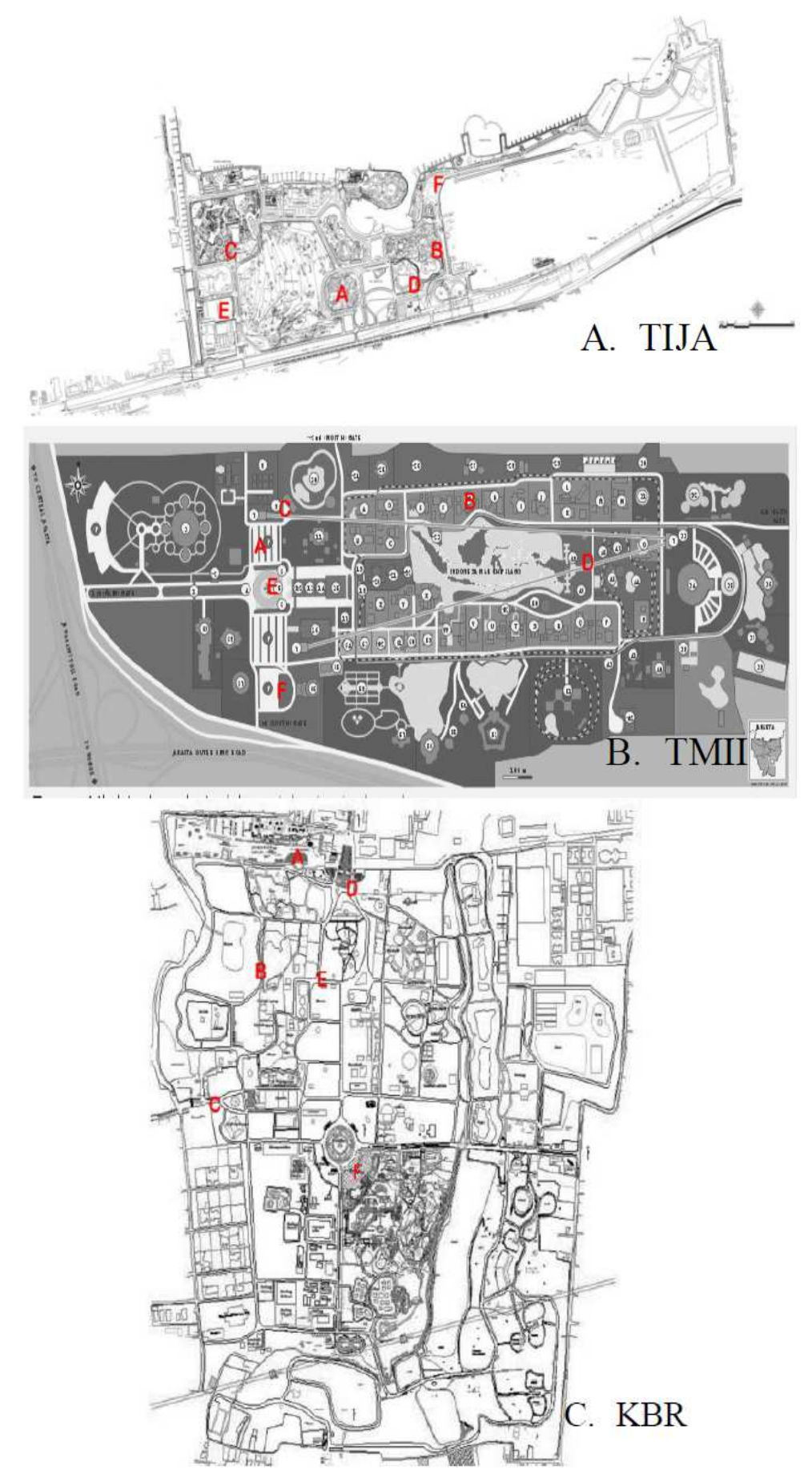

Fig. 3. Map of TIJA, TMII and KBR and the location (points) of measurement 


\section{Taman Mini Indonesia Indah (TMII)}

Taman Mini Indonesia Indah (TMII) is an area of approximately 250 square kilometers, located in East Jakarta, Indonesia $\left(6^{\circ} 18^{\prime} 6.8^{\prime \prime} \mathrm{S}, 106^{\circ} 53^{\prime} 47.2^{\prime \prime} \mathrm{E}\right)$, see Fig. 1. TMII is a culture-based recreational theme park. It is a representation of Indonesian culture captured in separate pavilions, with the collections of Indonesian architecture, clothing, dances and traditions. All are portrayed clearly all aspects of daily life in 26 provinces of Indonesia (1997). In the middle of the park, there is a lake with a miniature of the Indonesian archipelago and cable cars above, see Fig. 3. A part of the park there is a museum, Keong Emas Imax cinema, with theatre named My Homeland Theatre (Theater Tanah Airku) and other recreational facilities which make TMII one of the most popular for local tourist destinations in Jakarta. Culture, diversity in unity, is the theme brought to the visitors by TMII.

\section{Ragunan Zoo (Kebun Binatang Ragunan/KBR)}

Ragunan Park is a zoo located in the Ragunan area, South Jakarta, $\left(6^{\circ} 18^{\prime} 42.45^{\prime \prime} \mathrm{S}, 106^{\circ} 49^{\prime} 00.40^{\prime \prime} \mathrm{E}\right)$, see Fig. 1. The zoo area of 140 hectares was established in 1864, also known Ragunan Zoological Park, Ragunan Zoo consist of Zoo and Park area. There are many attractions in KBR e.g.; the Schmutzer Primate Centre is a special enclosed house with various primates, including gorillas, chimpanzees and orangutans. The 13-hectares (32-acres) part of the KBR area are in the children's playground area include a Children's Zoo, playground and animal rides, along with the Sunday events of elephant ride, pony cart and boat rides on Ragunan Lake and the orangutans watching deck on their daily tour of the zoo grounds in a pony cart. Restaurant facilities and picnic shelters are available for visitors' convenience as well as stands for purchasing souvenirs of the zoo, see Fig. 3.

\section{Research Objective and Methodology}

The Most Widely Used Thermal Indices at Present Time

Mayer and Hoppe (1987) stated PET (Physiological Equivalent Temperature) was used to calculate the thermal comfort index. PET is widely known using ${ }^{\circ} \mathrm{C}$ in its unit. Therefore, PET has the advantage compared to other thermal comfort index (Höppe, 1999; Matzarakis et al., 1999). Base on the human energy balance of the human body PET is a very good match to the human biometeorological evaluation of the thermal component in any different climates. Therefore, it is suitable to thermal physiologically and reproducible.

The thermal comfort model prompts eight-point scale, from very cold to very hot, combining individual parameters (metabolism and clothing resistance) and environmental parameters (air temperature, air humidity, air temperature and radiant temperature). This research used the PET index stated by Lin and Matzarakis (2008), which suitable for tropical region like Indonesia, see Table 1.

PET index was suitable used for those theme parks where the level of comfort can be obtained from the features of the urban environment that already present in those theme parks. Matzarakis et al. (1999) stated PET has been well-defined as a thermal index that serves the thermal component in different climates.

Table 1. Comparison of PET Index between moderate region and (sub) tropical region

\begin{tabular}{llll}
$\begin{array}{l}\mathrm{PET}^{\mathrm{a}} \text { moderate } \\
\text { region }\left({ }^{\circ} \mathrm{C}\right)\end{array}$ & $\begin{array}{l}\mathrm{PET}^{\mathrm{b}}(\mathrm{Sub}) \\
\text { Tropical region }\left({ }^{\circ} \mathrm{C}\right)\end{array}$ & Thermal perception & $\begin{array}{l}\text { Grade of } \\
\text { physiological stress }\end{array}$ \\
\hline 4 & 14 & Very Cold & Extreme Cold Stress \\
8 & 18 & Cold & Strong Cold Stress \\
13 & 22 & Cool & Moderate Cold Stress \\
18 & 26 & Slightly Cool & Slight Cold Stress \\
23 & 30 & Comfortable & No Thermal Stress \\
29 & 34 & Slightly Warm & Slight Heat Stress \\
35 & 38 & Warm & Moderate Heat Stress \\
41 & 42 & Hot & Strong Heat Stress \\
\hline
\end{tabular}

Source: ${ }^{a}$ Matzarakis and Mayer (1996), ${ }^{b}$ Lin and Matzarakis (2008) 


\section{Rayman Model}

Rayman model, developed by Matzarakis et al. (2007), was used as tools to calculate PET. This model enables estimate the mean radiant temperature, one of the most difficult parameters to calculate. Gulyas et al. (2006); and Lin et al. (2006) reported that Rayman can predict the thermal environment. It has been used to calculate in several of outdoor thermal comfort with complex shading patterns. Lin et al. (2010) reported, PET can be estimated using Ta (temperature), RH (Relative Humidity), v (wind velocity), Tmrt (Mean Radian Temperature), human clothing and activity in the model. Moreover, several parameters can be added to calculate following analyses, i.e., the Tmrt (the most important factor during hot condition when calculating PET) can be also estimated by global radiation ( $\mathrm{Gr}$ ), cloud cover $(\mathrm{Cd})$, fisheye photographs, albedo, the Bowen ratio of ground surface and the Link turbidity to include the shading effect while calculating short- and long-wave radiation fluxes. Besides variables above, the Sky View Factor (SVF) is another factor that affected the value of PET (Hwang et al., 2011).

Gómez et al. (2004) reported the value of clothing and activity were assumed to be constant to set up the index. This model did not mean that the model has a limitation, if they vary equally outdoors and in the standard of the indoor situation, the PET does not significantly affected.

\section{Outdoor Thermal Comfort Indices in Hot-Humid Climate}

There are two basic approaches Morgan and Baskett (1974) when we study thermal comfort: (1) Rational approach, using the human energy balance approach to the thermal comfort theory, (2) Empirical approach, in this approach meteorological variables is the key role to approach the thermal comfort. The variable of human activity, thermal physiology, clothes and human personal data (such as sex, weight, height, age) do not a concern.

Researchers show rational indices are widely used. (Matzarakis et al., 2007) studied the urban thermal comfort by calculating the mean radiant temperature and thermal indices in simple and complex environment. They calculated thermal comfort using Rayman model based on data of air temperature, humidity and wind velocity. Lin et al. (2012; 2013) studied thermal comfort in open spaces based on psychological factors in the perception of individual comfort.

Outdoor thermal comfort researches in hot-humid tropical country are still incipient. Lin and Matzarakis (2008) tried to find and identified hot-humid tropical region index scale by using research in outdoor thermal comfort in Taiwan. Their studies focused on modifying the thermal comfort indices from moderate climates of tropical and subtropical climate. The tolerance of higher neutral temperature of Taiwans resident related to PET values between 26 and $30^{\circ} \mathrm{C}$ compared to western/middle Europe scale between 19 and $23^{\circ} \mathrm{C}$. The comparison scale indices can be seen in Table 1 . Continue by Makeremi et al. (2012), they researched outdoor thermal comfort in Malaysia by comparing the shaded and non shaded area in the university in Malaysia. They used comfort index of tropical climate from Lin and Matzarakis (2008). Makeremi et al. (2012) showed the result that PET values in selected shaded outdoor spaces were higher than the comfort range defined for tropical climate $\left(\mathrm{PET}<30^{\circ} \mathrm{C}\right.$ ). The normal condition that can be accepted, in a range of comfortable (PET $<34^{\circ} \mathrm{C}$ ) occurred during the early hours of measurement (9-10 am) and late afternoon (4-5 pm). Shading that obtained by the vegetation and surrounding the buildings is the area that had the longer thermal comfort acceptable period.

\section{Research Objectives}

The following condition of this research had to be taken into account: The locations of the research; human-biometeorology; the factors of specific condition in the theme parks that affecting and distorting some meteorological component; the characteristic of each index regarding to their model and component.

The methodology of this research was to precisely measure the meteorology's variables, which became input data for the Rayman model, once the suitable locations had been chosen for this research and the different situation described for each of the objectives. This research objective is: Establishing the comfort level of theme parks in different location and situation in hothumid climate theme parks.

\section{Field Measurement}

A sunny day without rain is an essential day to measure in an outdoor environment. The meteorological variables (temperature, humidity and wind velocity) are measured based on the climate condition in Jakarta, see Fig. 2. The range of the hottest month in the dry season and the coldest month in the rainy season were the best choice to carry out the meteorological parameters measurement. According to the permission and suggestion from the three Theme Parks Management, they chose March and September that were able to carry out the field measurement in the parks. Those month are chosen not only the permission, but also the best month of local visitors; most of them are people from Jakarta who want to enjoy and relax; attends to the theme parks. Thus, in this research, March and September were chosen to be the best condition. March is the month that still in the range of coldest month in Jakarta; the coldest month range in Jakarta is January-February-March (Fig. 
2). September is the month that still in the range of the hottest month in Jakarta; the hottest month range in Jakarta is September-October-November (Fig. 2).

Data was collected on two consecutive years (20132014). The measurements were made on 21 March and 19 September, during $10 \mathrm{~h}$, between $7.00 \mathrm{AM}$ to 17.00 , regarding theme parks were opened. The Locations of measurement are shown in Fig. 2.

The following equipment: LM 8000, the surface temperature measuring device and EM 528A are used during field measurements. All sensors installed in $1.5 \mathrm{~m}$ above the ground and under factory calibrated. All Data results were made every $10 \mathrm{~min}$.

\section{Sky View Factor}

Shading influences the thermal environment and human thermal comfort in the outdoor environment, thus, affecting the usage of outdoor spaces. Lin et al. (2012) made study using the average-Sky View Factor (SVFa) than the traditional sky view factor from fisheye photographs (SVFsp) in the park. The result showed that the lower SVFa, the higher the parks utilization. They stated that the importance of the shading design in the parks located in the tropical or subtropical climates. Paramita and Fukuda (2014) stated that SVF and Tmrt have significant correlation. Thus, urban form is related to the heat intensity exposure in hot-humid climate region.

Lin et al. (2010) had the research results that the area with high SVF, unshaded area, have a greater frequency of uncomfortable during the summer compared to the shaded area. Kántor and Unger (2011) stated in their study that people tend to move to shaded areas when the thermal condition is warm or hot. Regarding shading levels and area, this study quantified the shade area using the SVF values evaluated from fisheye photographs.

In this research SVF was measured using images taken with one set of photographic equipment: A conventional camera (Nikon D80) with a fisheye hemispheric lens (Tokina $10 \mathrm{~mm} \mathrm{f4}$ ). The image from the camera was transferred to the Sky View Factor Calculator. Brown et al. (2001) stated that Sky View Factor Calculator is able to calculate the Sky View Factor (SVF) value on hemispherical photographs using a Graphical User Interface (GUI).

Lindberg and Holmer (2006) reported in Manual Book of Sky View Factor Calculator version 1.1, the method of calculation in Sky View Factor Calculator based on two methods, first is the annulus method as presented in Johnson and Watson (1984) and the second is pixel-based method developed by Holmer et al. (2001). Based on two methods the results of SVF value were similar in this measurement, see Fig. 5.

The six point measurement was conducted in each park and divided into 3 groups with respect to their different shaded area conditions based on Sky View Factor (SVF) value. The first group is the dense greenery (DG, $\mathrm{SVF}<40 \%$ ), the second group is Light greenery (LG, $40 \%<\mathrm{SVF}<70 \%$ ) and the third group is sparse dense greenery (SG, 70\% $<\mathrm{SVF}<100 \%$ ), see Fig. 5 .

\section{Results and Discussion}

\section{The Effect of Macroclimate}

Figure 6 shows, during the days of measurement in March and September, Jakarta's thermal comfort was affected by macroclimate condition which shown uncomfortable. The data of Jakarta's macroclimate were accepted from two big weather stations from 2012-2014, Soekarno-Hatta International Airport weather station and Halim Perdana Kusuma Airpot.

Average PET values in Jakarta were above $30^{\circ} \mathrm{C}$ starts from $11 \mathrm{AM}$ and reached $45^{\circ} \mathrm{C}$ at $3 \mathrm{PM}$, although in the morning at 07.00 was still in a comfortable condition, $22^{\circ} \mathrm{C}$ PET, these conditions change quickly became uncomfortable in the afternoon, see Fig. 6 .

Every district in Jakarta is affected by Macroclimate condition of Jakarta. Macroclimate on 19 September and 21 March, shows that the average temperature was at $28^{\circ} \mathrm{C}$ varied from $24^{\circ} \mathrm{C}$ to $32^{\circ} \mathrm{C}$. The morning temperature started at $24^{\circ} \mathrm{C}$ where the temperature is the influence of the previous day with $95 \%$ humidity and wind speed $0 \mathrm{~m} \mathrm{sec}^{-1}$.

\begin{tabular}{|c|c|c|}
\hline $\begin{array}{c}\text { PET } \\
\text { Tropical Region } \\
{ }^{\circ} \mathrm{C} \\
\end{array}$ & $\begin{array}{l}\text { Thermal } \\
\text { Perception }\end{array}$ & $\begin{array}{c}\text { Grade of } \\
\text { Physiological } \\
\text { Stress }\end{array}$ \\
\hline \multirow{2}{*}{42} & Very Hot & Extreme Heat \\
\hline & Hot & Strong Heat Stress \\
\hline 38 & Warm & Moderate Heat \\
\hline \multirow[t]{2}{*}{34} & & Stitess \\
\hline & Slightly Warm & Slight Heat Stress \\
\hline 30 & Comfortable & No Thermal Stress \\
\hline 26 & Slightly Cool & Slight Cold Stress \\
\hline 22 & Cool & $\begin{array}{l}\text { Moderate Cold } \\
\text { Stress }\end{array}$ \\
\hline 18 & Cold & Strong Cold Stress \\
\hline 14 & Very Cold & $\begin{array}{l}\text { Extreme Cold } \\
\text { Stress }\end{array}$ \\
\hline
\end{tabular}

Fig. 4. The color of comfortable scale based on Lin and Matzarakis (2008) scale 
The pattern of PET value between Jakarta and the theme parks are similar. The macroclimate condition of Jakarta moreover affect the microclimate condition in the theme parks as seen in Fig. 5. The three big theme parks did not achieve the expected thermal comfort during the measurement, average comfort condition only occurs $2 \mathrm{~h}$ in the morning at $7 \mathrm{AM}$ to 9 $\mathrm{AM}$, after $9 \mathrm{AM}$ the areas grew up to be hotter, start from $29^{\circ} \mathrm{C}$ and reached the peak uncomfortable condition at $2 \mathrm{PM}, 45^{\circ} \mathrm{C}$.

As we had foreseen in Fig. 7, the PET values in September are higher than in March. The reason of this is that in September the temperature increased and the rainfall season started in Jakarta, humidity increased respectively. PET values in the three big parks illustrates that thermal comfort tends to increase along with the hot temperatures, high humidity and low wind velocity in Jakarta. In March, the condition is more comfortable and the condition just little bit more comfort than in September.

From the Fig. 7 shows PET inside the parks still lower than the PET condition in Jakarta, Fig. 4 was taken from the Soekarna-Hatta Airport Weather Station and Halim Perdana Kusuma Airport Weather Station during the 2 years from 2012-2014. In whole years thermal comfort condition is not much different in Jakarta.

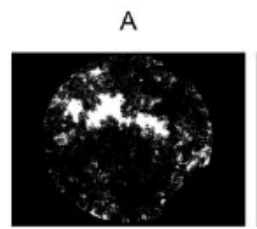

SVF $18 \%$

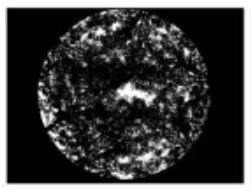

SVF $17 \%$



SVF $8 \%$
B

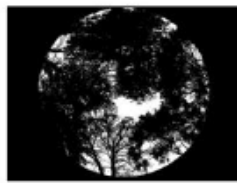

SVF $12 \%$

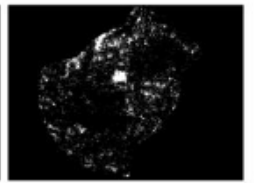

SVF $10 \%$

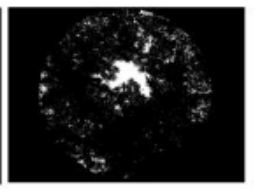

SVF $13 \%$
C

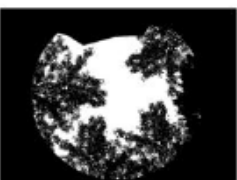

SVF $56 \%$

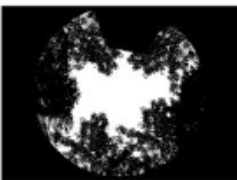

SVF $51 \%$

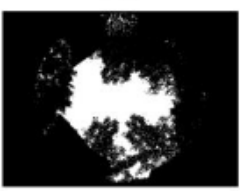

SVF $47 \%$
D

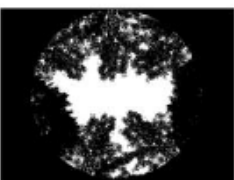

SVF $54 \%$

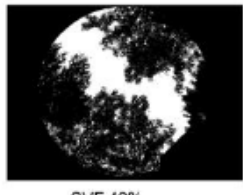

SVF $42 \%$

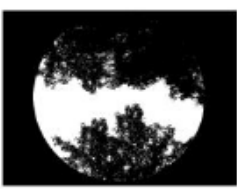

SVF $46 \%$

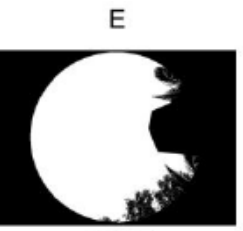

SVF $89 \%$



SVF $90 \%$

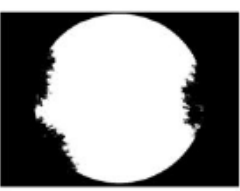

SVF $98 \%$

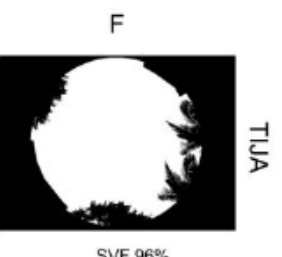

SVF $96 \%$

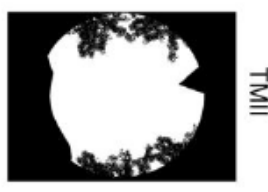

SVF $92 \%$

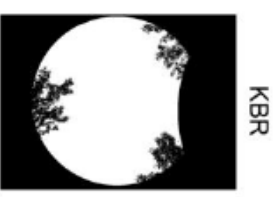

SVF $93 \%$

Fig. 5. Sky view factor values based on Sky View Factor Calculator by Lindberg and Holmer (2006)
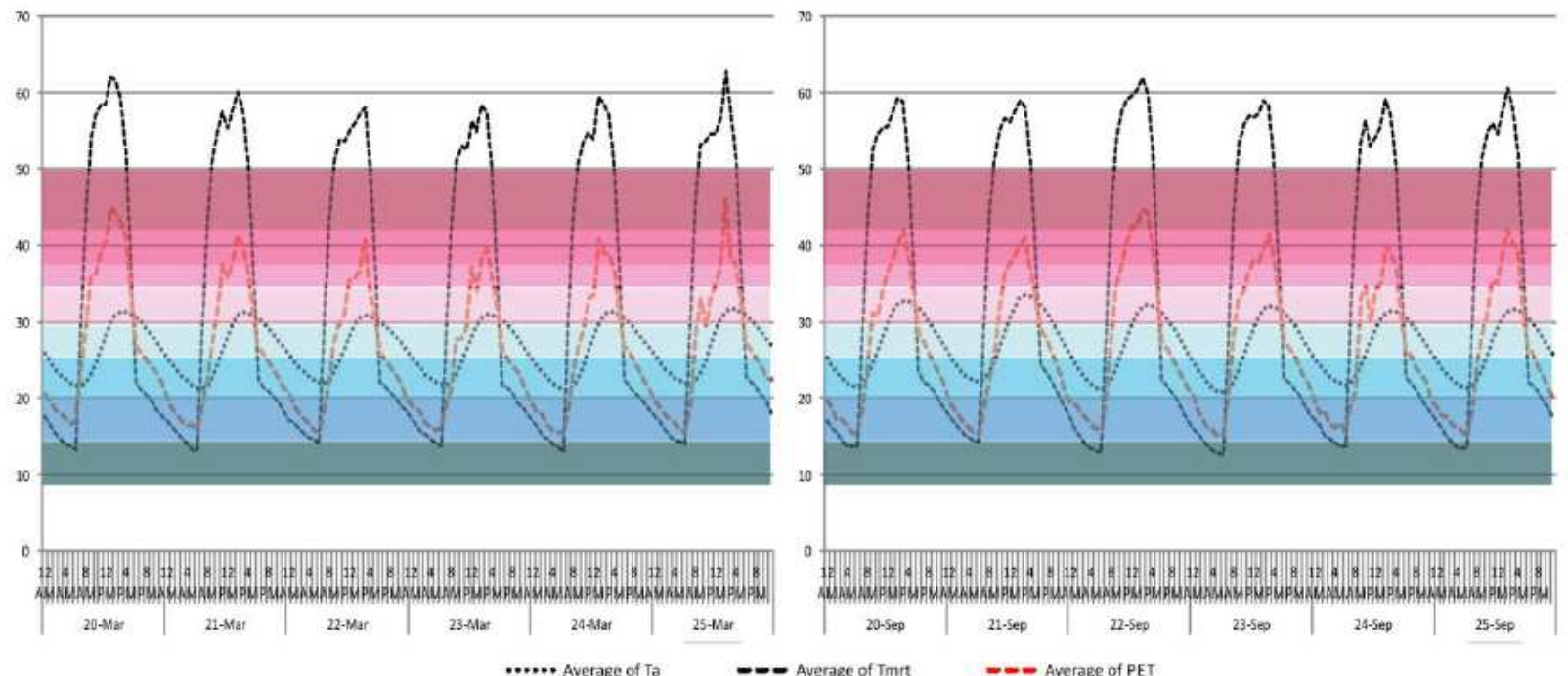

Fig. 6. Average Ta, Tmrt and PET of Jakarta calculated by Rayman software based on weather data 2012-2014 show the results at the day of field measurement (March 20-25th and September 20-25th) 


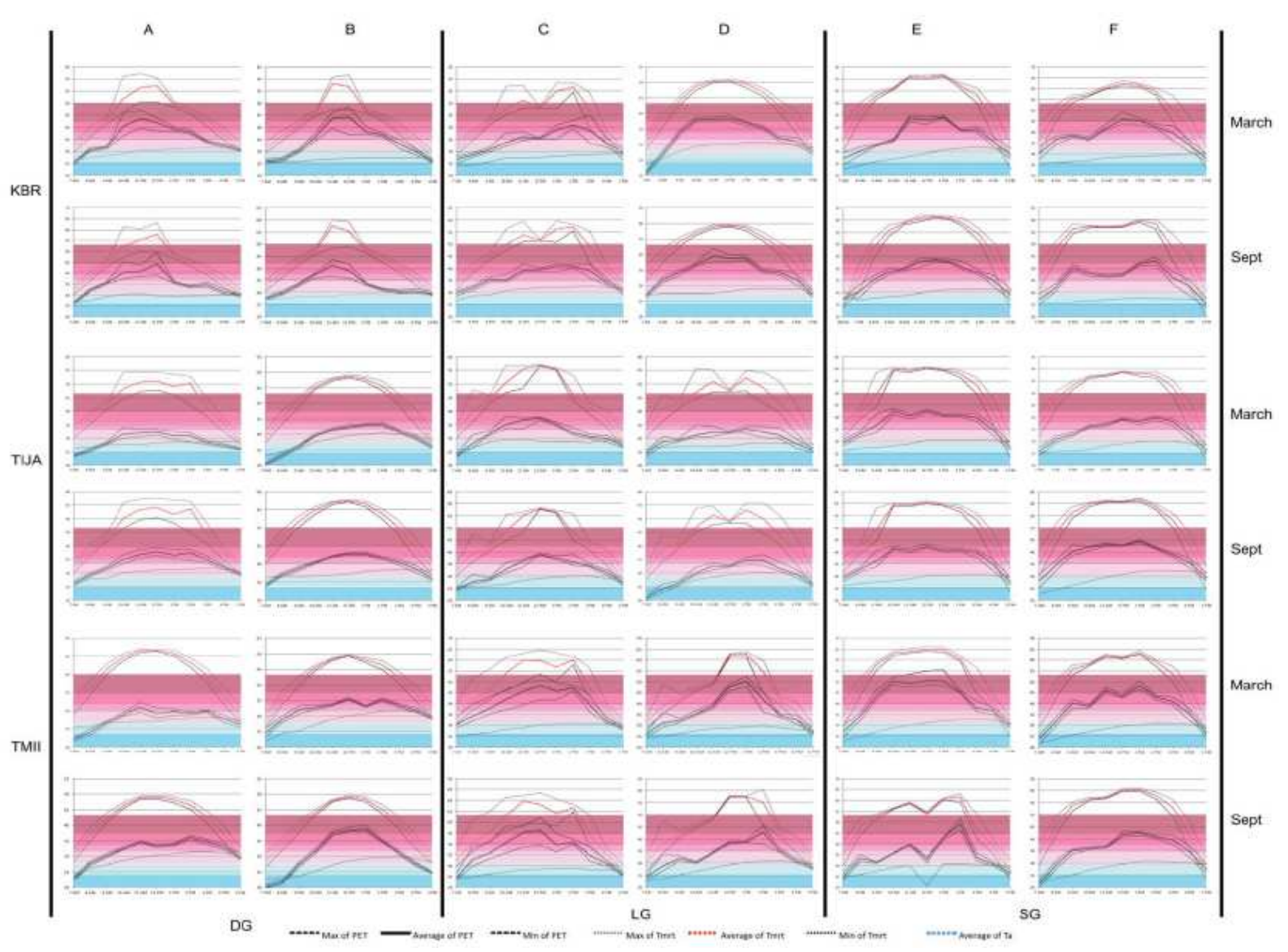

Fig. 7. PET values, average Tmrt and Ta of measurement result of three big theme parks (TIJA, TMII, KBR) at March 21 st and September 19th from 7 AM to 5 PM

\section{Correlation SVF and Thermal Comfort}

The field measurement indicated that the average air temperature between $7 \mathrm{AM}$ and 5 PM was above the required comfort level of air temperatures, whereas the neutral air temperature needs to be maintained at $28.2^{\circ} \mathrm{C}$ to reach the thermal comfort (Humphreys and Nicol, 2001).

Average Relative Humidity was about $90 \%$ at 7 AM, $65 \%$ at $2 \mathrm{PM}$ and went up to $80 \%$ in $5 \mathrm{PM}$. At $7 \mathrm{AM}$ averages $\mathrm{Rh}$ almost same, Rh difference between $\mathrm{SG}$ and DG are about $20 \%$ at 3 PM. The results emphasized the highest relative humidity in DG area. The air velocity fluctuated from 1 to $6 \mathrm{~m} \mathrm{sec}^{-1}$. DG area air velocity can reach $6 \mathrm{~m} \mathrm{sec}^{-1}$ at $4 \mathrm{PM}$, in the DG average air velocity from $7 \mathrm{AM}$ to $3 \mathrm{PM}$ is stable about $3 \mathrm{~m} \mathrm{sec}^{-1}$, in $\mathrm{SG}$; air velocity at $7 \mathrm{AM}$ is lowest $0.5 \mathrm{~m} \mathrm{~s}^{-1}$.

The PET values of Less Greenery (LG) are higher than Dense Greenery (DG). The reason of this is that in LG there is greater capacity of heat accumulation, in the surface and the ambient, because of the openness area. In this case LG areas have a benefit of the wind velocity at least can refresh the area from the heat. Otherwise DG areas are closer to the wind, thus the wind velocity is slower, but giving rise to a lower radiation value.

According to overall measurement in the selected areas, the acceptable range of thermal comfort less than $34^{\circ} \mathrm{C}$ ) occurred at 7-10 AM (early morning) and 3-5 pm (late afternoon). However, in the shaded area $(\mathrm{SVF}<34 \%)$, thermal comfort is acceptable one hour longer from 7-11 am. The study also found that thermal comfort at 11 am-4 pm was the situation at the lowest level of thermal comfort due to the high amount of exposure of solar radiation.

Dense Greenery (DG) mean the $\mathrm{SVF}<40 \%$ shows the radiation exposure in that area, under the vegetation, is very small compared to the LG and SG. Although there was a considerable difference in thermal comfort condition, the thermal comfort index (PET) values show Tmrt (solar radiation) is the key role that affected the thermal comfort in the parks than Ta (air temperature). The result shows that the temperature alone is not much appropriate for evaluation of thermal comfort in an outdoor environment. These results match the findings of previous studies (Makaremi et al., 2012; Mayer et al., 2008; Ali-Toudert and Mayer, 2007). 
Wind velocity is affected in the area where the $\mathrm{SVF}<40 \%$, DG. Vegetation hinders the wind velocity that goes to the area. Wind velocity in the DG is slower than in the area in LG and SG. Nevertheless, wind velocity is not much affected the thermal comfort values (PET). The measurement shows that the variation of thermal comfort index (PET) was mostly affected by Tmrt rather than Ta, or wind velocity. It should be noted, although, wind velocity can decrease the values of PET, but Tmrt is the key role when calculating thermal indices in hot-humid climates.

This study also illustrates that to protect the area from the exposure of solar radiation plant the vegetation and the use of tree have to be taken into account in an outdoor environment. Shaded area decreases the PET values by reducing the solar radiation. Accordingly, the areas protected by the shade under the vegetation and surrounding buildings tend to be more comfortable than the other due to their lower exposure to direct solar radiation. Thus, the shaded areas are important in the outdoor environment to increase the thermal comfort and lengthen the acceptance of the thermal condition during the day.

The wide range of microclimatic conditions in TIJA, TMII and KBR strengthens the point that a purely physiological approach is inadequate to characterize thermal comfort conditions outdoors, whereas the issue of adaptation becomes increasingly important.

\section{Conclusion}

This study focuses on the meteorological measurement of three theme parks in Jakarta and discussed the thermal comfort condition in the outdoor environment in the context of hot-humid climates. The measurement investigates the outdoor thermal comfort in term of environmental condition and human comfort level.

The comparison of all areas shows that the best thermal comfort conditions occur in Dense Greenery (DG, $\mathrm{SVF}<40 \%)$. This research has proven that comfort is mainly affected by exposure of solar radiation. Shaded areas in parks during measurements provided comfort slightly better than areas that are not shaded. Vegetation provides shadowing can be considered not only as an element of design, but also provides thermal comfort during the day.

By researching these case studies, it has been concluded that PET index mostly suitable to measure the thermal comfort, because it can clearly depict the variation of meteorological and humanbiometeorological parameters in different image of thermal comfort in hot-humid tropical parks. The PET values in this study showed that the acceptance thermal comfort, PET $<34^{\circ} \mathrm{C}$, occurred in the early morning (7-10 $\mathrm{am} / 3 \mathrm{~h})$ and late afternoon (3-5 PM/2 h). Meanwhile, a longer thermal comfort-acceptance period $(4-5 \mathrm{~h})$ occurred in the shaded areas under the vegetation and surrounding buildings, due to their lower solar radiation.

The research is valuable regarding to the information of human thermal comfort in an outdoor environment of hot-humid climates. In conclusion, this result is very important for architects, urban planners and landscape designers, who concerned to find better design, especially to theme parks for more livable and generally for open space in the cities.

\section{Acknowledgement}

To all the peoples which took part in the field work and helped in the organization of the collected data. Thanks to Professor Weijun Gao from the Faculty of Environmental Engineering, University of Kitakyushu for the discussions that preceded this field work. Finally, we would like to also thank the Faculty of Environmental Engineering, University of Kitakyushu, Japan; School of Architecture, Planning and Policy Development, Institute Technology of Bandung, Indonesia; and DIKTI (Directorate General of Higher Education) Indonesia for financially supporting this research work.

\section{Author's Contributions}

M. Donny Koerniawan, as the first author, designed and conducted the research, including data collectors recruitment, data planning development, data collection and data analysis. M. Donny Koerniawan prepared the draft of the manuscript with intellectual input from Prof. Dr. Weijun Gao, as a supervisor of the first author at The University of Kitakyusu, Japan. The data analyzing input were supported from Prof. Dr. Weijun Gao. The Directorate General of Higher Education of Indonesia provided funding of this research during the doctoral program at The University of Kitakyushu, Japan. All the authors approved the final manuscript.

\section{Ethics}

As a researcher and now, a doctoral candidate in the University of Kitakyushu, Japan, I am aware in a position of responsibility and trust. Therefore, when I conducted this research, I applied the highest ethical standard, maintained the highest integrity at all times regarding data gathering and reported the true information through analysis. I avoid plagiarism and fully acknowledge the works of others to which I referred in my paper. 


\section{References}

Akbari, H., M. Pomerantz and H. Taha, 2001. Cool surfaces and shade trees to reduce energy use and improve air quality in urban areas. Solar Energy, 70: 295-310. DOI: 10.1016/S0038-092X(00)00089-X

Akbari, H., S. Menon and A. Rosenfeld, 2009. Global cooling: Increasing world-wide urban albedos to offset $\mathrm{CO}_{2}$. Climatic Change, 94: 275-286.

DOI: $10.1007 / \mathrm{s} 10584-008-9515-9$

Ali-Toudert, F. and H. Mayer, 2007. Effects of asymmetry, galleries, overhanging façades and vegetation on thermal comfort in urban street canyons. Solar Energy, 81: 742-754.

DOI: 10.1016/j.solener.2006.10.007

Brown, M.J., S. Grimmond and C. Ratti, 2001. Comparison of methodologies for computing sky view factors in urban environments. Proceedings of the International Symposium on Environmental Hydraulics, (SEH' 01), ISEH and IAHR.

Bruse, M., 2007: Simulating human thermal comfort and resulting usage patterns of urban open spaces $w$ ith a Multi-Agent System. Proceedings of the 24th International Conference on Passive and Low Energy Architecture, (LEA' 07), pp: 699-706.

Chen, L. and E. Ng, 2012. Outdoor thermal comfort and outdoor activities: A review of research in the past decade. Cities, 29: 118-25.

DOI: 10.1016/j.cities.2011.08.006

Eliasson, I., 2000. The use of climate knowledge in urban planning. Landscape Urban Plann., 48: 31-44. DOI: 10.1016/S0169-2046(00)00034-7

Gulyas, A., J. Unger and A. Matzarakis, 2006. Assessment of the microclimatic and human comfort conditions in a complex urban environment: Modelling and measurements. Build. Environ., 41: 1713-1722. DOI: 10.1016/j.buildenv.2005.07.001

Gómez, F., L. Gil and J. Jabaloyes, 2004. Experimental investigation on the thermal comfort in the city: relationship with the green areas, interaction with the urban microclimate. Build. Environ., 39: 1077-1086. DOI: 10.1016/j.buildenv.2004.02.001

Honjo, T., 2009. Thermal comfort in outdoor environment. Global Environ. Res., 13: 43-47.

Höppe, P.R., 1999. The physiological equivalent temperature-a universal index for the biometeorological assessment of the thermal environment. Int. J. Biometeorol., 24: 699-706. DOI: $10.1007 / \mathrm{s} 004840050118$

Holmer, B., U. Postgård and M. Eriksson, 2001. Sky view factors in forest canopies calculated with IDRISI. Theoretical Applied Climatol., 68: 33-40. DOI: $10.1007 / \mathrm{s} 007040170051$
Humphreys, M.A. and J.F. Nicol, 2001. The validity of ISO-PMV for predicting comfort votes in every-day thermal environments. Energy Build., 34: 667-684. DOI: $10.1016 / \mathrm{S} 0378-7788(02) 00018-\mathrm{X}$

Hwang, R.L., T.P. Lin and A. Matzarakis, 2011. Seasonal effects of urban street shading on longterm outdoor thermal comfort. Build. Environ., 46: 863-870.

DOI: $10.1016 /$ j.buildenv.2010.10.017

Johnson, G. and I. Watson, 1984. The determination of view-factors in urban canyons. J. Climate Applied Meteorol., 23: 329-335. DOI: 10.1175/15200450(1984)023<0329:TDOVFI >2.0.CO;2

Kántor, N. and J. Unger, 2011. Benefits and opportunities of adopting GIS in thermal comfort studies in resting places: An urban park as an example. Landscape Urban Plann., 98: 36-46. DOI: 10.1016/j.landurbplan.2010.07.008

Landsberg, H.E., 1981. The Urban Climate. 1st Edn., Academic Press, New York. ISBN-10: 0080924190, pp: 275.

Lindberg, F. and B. Holmer, 2006. Sky view factor calculator user manual-version 1.1. University of Gothenburg.

Lin, T.P., A. Matzarakis and J.J. Huang, 2006, Thermal comfort and passive design of bus shelters. Proceedings of the 23rd Conference on Passive and Low Energy Architecture, Sept. 6-8, Geneva, Switzerland.

Lin, T.P. and A. Matzarakis, 2008. Tourism climate and thermal comfort in Sun Moon Lake, Taiwan. Int. J. Biometeorol., 52: 281-90. DOI: $10.1007 / \mathrm{s} 00484-007-0122-7$

Lin, T.P., A. Matzarakis and R.L. Hwang, 2010. Shading effect on long-term outdoor thermal comfort. Build. Environ., 45: 213-221. DOI: $10.1016 /$ j.buildenv.2009.06.002

Lin, T.P., K.T. Tsai, R.L. Hwang and A. Matzarakis, 2012. Quantification of the effect of thermal indices and sky view factor on park attendance. Landsc. Urban Plan., 107: 137-146.

DOI: 10.1016/j.landurbplan.2012.05.011

Lin, T.P., K.T. Tsai, C.C. Liao and Y.C. Huang, 2013. Effects of thermal comfort and adaptation on park attendance regarding different shading levels and activity types. Build. Environ., 59: 599-611. DOI: 10.1016/j.buildenv.2012.10.005

Makaremi, N., E. Salleh, M.Z. Jaafar and A.H. GhaffarianHoseini, 2012. Thermal comfort conditions of shaded outdoor spaces in hot and humid climate of Malaysia. Build. Environ., 48: 7-14. DOI: 10.1016/j.buildenv.2011.07.024 
Matzarakis, A. and H. Mayer, 1996. Another kind of environmental stress: Thermal stress. WHO collaborating centre for air quality management and air pollution control. Newsletters, 18: 7-10.

Matzarakis, A., H. Mayer and M.G. Iziomon, 1999. Applications of a universal thermal index: Physiological equivalent temperature. Int. J. Biometeorol., 43: 76-84.

DOI: $10.1007 / \mathrm{s} 004840050119$

Matzarakis, A., F. Rutz and H. Mayer, 2007. Modelling radiation fluxes in simple and complex environments-application of the RayMan model. Int. J. Biometeorol., 51: 323-334. DOI: $10.1007 / \mathrm{s} 00484-006-0061-8$

Mayer, H. and P.R. Höppe, 1987. Thermal comfort of man in different urban environments. Theory Applic. Climatol., 38: 43-49. DOI: 10.1007/BF00866252

Mayer, H., J. Holst, P. Dostal, F. Imbery and D. Schindler, 2008. Human thermal comfort in summer within an urban street canyon in Central Europe. Meteorol. Z., 17: 241-250. DOI: 10.1127/0941-2948/2008/0285

Mishra, A.K. and M. Ramgopal, 2013. Field studies on human thermal comfort-an overview. Build Environ., 64: 94-106.

DOI: $10.1016 /$ j.buildenv.2013.02.015
Morgan, D.L. and R.I. Baskett, 1974. Comfort of man in the city. An energy balance model of manenvironment coupling. Int. J. Biometeorol., 18: 184-198. DOI: $10.1007 /$ BF01453933

Oke, T.R., 1984. Towards a prescription for the greater use of climatic principles in settlement planning. Energy Build., 7: 1-10. DOI: $10.1016 / 0378-7788(84) 90040-9$

Oke, T.R., 2006. Initial guidance to obtain representative meteorological observations at urban sites. World Meteorological Organization (WMO), Instruments and Observing Methods, Report No. 81.

O'Hare, D., 2006. Urban walkability in the subtropical city: Some intemperate considerations from SEQ. Proceedingss of the Conference on Achieving Ecologically Sustainable Urbanism in a Subtropical Built Environment, Sept. 27-29, Brisbane, Queensland, Australia.

Paramita, B. and H. Fukuda, 2014. Heat intensity of urban built environment in hot humid climate region. Am. J. Environ. Sci., 10: 210-219. DOI: $10.3844 /$ ajessp.2014.210.218 